\title{
THE TEMPERATURE COEFFICIENT OF RESISTANCE OF COPPER
}

\author{
By J. H. Dellinger
}

\section{CONTENTS}

I. Introduction.

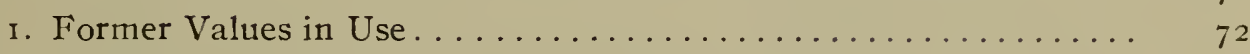

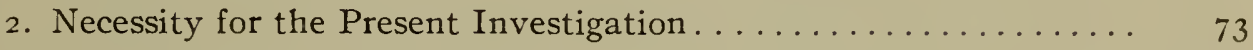

II. Experimental Data . . . . . . . . . . . . . . . . . . 73

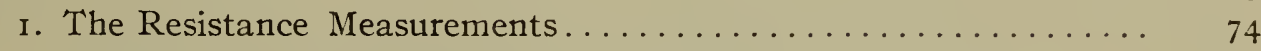

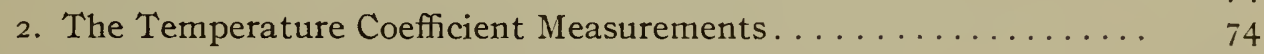

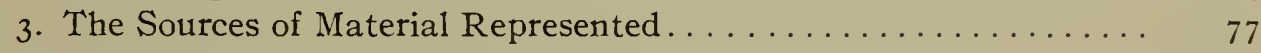

4. Effect of Chemical Differences of Samples............... 78

5. Effect of Physical Differences of Samples............... 79

6. Effect of Local Hardening. .................... 80

7. Copper Samples that had never been Melted ............ 8 I

III. Conclusions . . . . . . . . . . . . . . . $8_{3}$

I. Proportionality of Temperature Coefficient and Conductivity .... 83

2. The Resistivity-Temperature Constant............... 84

3. Temperature Correction for Measurements against a Copper

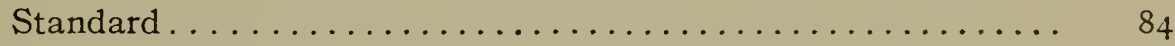

4. Effect of Hardening, Impurities, and Distortion on the Temperature Coefficient.......................... 85

5. The Temperature Coefficient as a Measurement of Conductivity"... 86

a. Odd Shapes.......................... 86

b. Short Samples............................ 86

c. Wires that have been Distorted and Bent.......... 86

d. The Estimation of Chemical Purity ............. 87

6. Explanation of Disagreements of Previous Observers ......... 87

7. Values Suggested for Annealed and Hard-Drawn Copper....... 88

IV. The Mathematical Expression of the Temperature Coefficient......... 88

I. On General Functions of Temperature.............. 88

2. Calculation of Linear Temperature Coefficient from Observations. . 92

3. Effect of Thermal Expansion in the Expression of the Linear

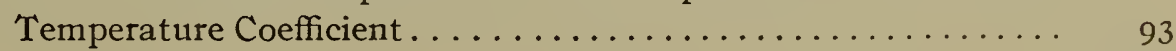

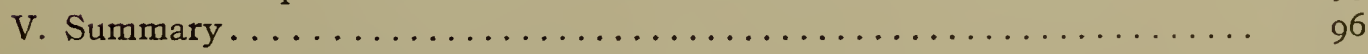

VI. Appendix.-Reichsanstalt Results...................... 97 


\section{INTRODUCTION}

1. FORMER VALUES IN USE

Widely varying values are in use for the temperature coefficient of resistance of copper. Some of those which have been much used are given in the following table, in which $\alpha_{0}$ and $\alpha_{20}$ are given respectively by the equations:

$$
R_{t}=R_{0}\left(\mathrm{I}+\alpha_{0} t\right) \quad R_{t}=R_{20}\left(\mathrm{I}+\alpha_{20}[t-2 \mathrm{O}]\right)
$$

$R_{0}, R_{20}, R_{t}=$ resistance respectively at $0^{\circ} \mathrm{C}$, at $20^{\circ} \mathrm{C}$, and at $\mathrm{t}^{\circ}$. $\mathrm{t}=$ any temperature centigrade.

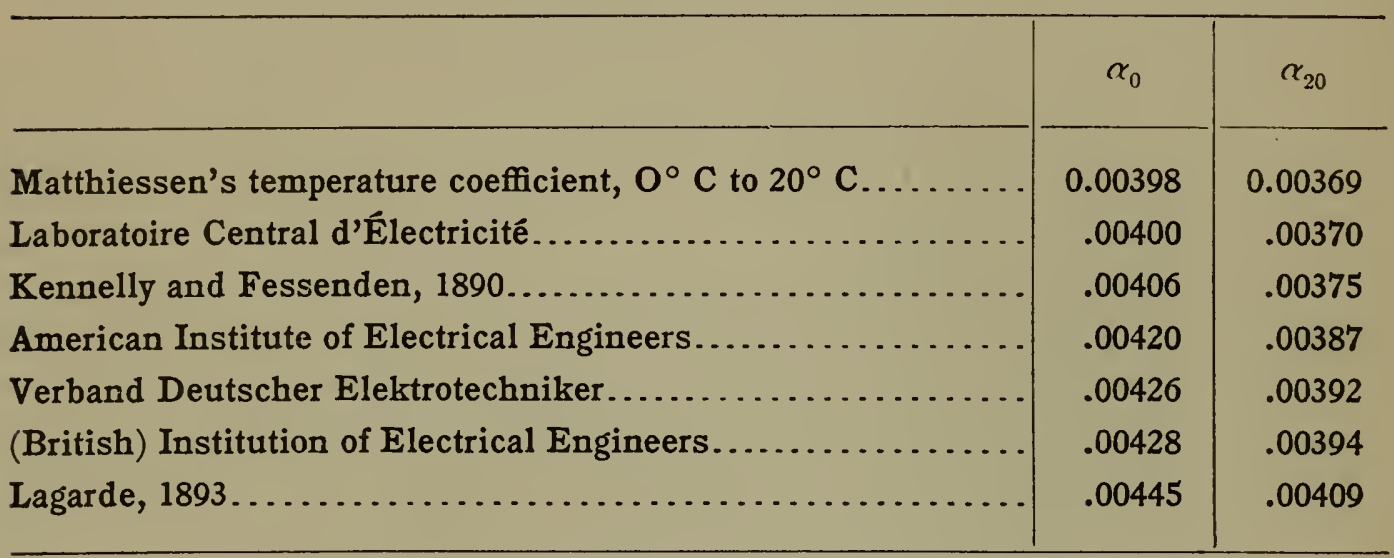

Matthiessen's formula is: $\lambda_{t}=\lambda_{\mathrm{o}}$ (I-0.003870 $t$ to.000009009 $t^{2}$ ). $\lambda_{t}$ and $\lambda_{\mathrm{o}}=$ conductivity, or reciprocal of resistance, at $t^{\circ}$ and $o^{\circ} \mathrm{C}$, respectively.

The second value given is that used by French engineers. The value given by the American Institute of Electrical Engineers has also been assumed by the Bureau of Standards. The value given by the Verband Deutscher Elektrotechniker has been in general use in Germany since I896, and was obtained by assuming $\alpha_{15}=$ o.004. The relations between $\alpha_{0}^{\prime}, \alpha_{15}$, etc., are given in Section IV of this paper. 'The British Institution of Electrical Engineers' value is based on the measurements of Clark, Ford, and Taylor, in 1899 , and happens to be the same as that determined by Dewar and Fleming in 1893 . Matthiessen's two-term formula, published in $\mathrm{r} 862$, is given in terms of conductivity instead of resistance, and has been used probably more than any other. Inasmuch as a linear formula suffices to express the accuracy of all work done up to the present for moderate temperature ranges, and as the many digits of Matthiessen's coefficients are without significance (the first being the mean of a number of values ranging from $0.003735 \mathrm{I}$ to 0.0039954 ), it is evident that the further use of this formula is undesirable. 


\section{NECESSITY FOR THE PRESENT INVESTIGATION}

The variations of the values in the above table may be considered to be due either to errors of the measurements made in establishing them or to differences in the temperature coefficients of different samples of copper. In either case, accurate results can not be expected when one of these values is taken as fixed and used for all samples. That this fact is not recognized is shown by the common practice of assuming that the temperature coefficient is the same for different samples of copper, while the conductivity is usually measured. It was accordingly considered of importance to determine whether the temperature coefficient of different samples does vary, and also to find whether there is any simple relation between the conductivity and the temperature coefficient.

An investigation has been carried out with the above in view upon samples of copper which represent a considerable number of the chief sources of supply of the copper used for electrical purposes and which include the native metal, that refined by smelting, and that refined by electrolysis. The results show that there are variations of the temperature coefficient, and that to a fair accuracy the relation of conductivity to temperature coefficient is a simple proportionality. This relation is in corroboration of the results of Matthiessen and others for differences in conductivity caused by chemical differences in samples; but the present results show that it holds for both physical and chemical differences. Thus, harddrawing and annealing, even more exactly than changes in chemical composition, cause proportional changes in conductivity and temperature coefficient.

\section{EXPERIMENTAL DATA}

The experimental work was carried out with wires, sizes 6 to I 2, Brown \& Sharpe gage, of about $\mathrm{r} 20 \mathrm{~cm}$ length. The resistivity and percent conductivity were computed from measurements of the length, mass, and resistance. The resistivity is given in ohms per meter-gram by multiplying the resistance per meter by the mass per meter. The "percent conductivity" is calculated on the assumption of IOO percent conductivity corresponding to a resistivity of $0.153022 \mathrm{ohm}$ per meter-gram at $20^{\circ} \mathrm{C}^{1} \quad$ According

1 This is the value assumed by the Bureau of Standards as representing "Matthiessen's standard," an arbitrary standard in wide use commercially. This value corresponds also to 1.72128 micro-ohms per centimeter cube at $20^{\circ} \mathrm{C}$ on an assumed density of 8.89 . 
to practice that is now very general in scientific work, $20^{\circ} \mathrm{C}$ is used as the standard temperature instead of $0^{\circ} \mathrm{C}$. The final results will be given, however, for $0^{\circ} \mathrm{C}, 15^{\circ} \mathrm{C}, 20^{\circ} \mathrm{C}$, and $25^{\circ} \mathrm{C}$, and they can be computed for any temperature.

\section{THE RESISTANCE MEASUREMENTS}

For the resistance measurements the wires were placed in a specially designed oil bath with provisions for efficient stirring of the oil, for heating and cooling, and for temperature regulation. The wire was held between heavy clamps through which the current was introduced. For conductivity determinations the resistance was measured between knife edges mounted I meter apart on the marble base. The Thomson bridge method was used for measuring the resistances, employing a double set of variable ratio coils; an accuracy of $\mathrm{I}$ in $\mathrm{I} 0 \mathrm{OoO}$ was easily attained. The resistance of the copper sample was compared with the resistance of a copper standard in the same bath as the test sample. The copper standards were wires carrying soldered potential leads and placed in frames having connections for both current and potential leads. These connections dropped into mercury cups on the marble base in the oil bath. The resistances of the copper standards were compared from time to time with manganin resistance standards which were kept in a separate oil bath. The method of comparing the copper samples with a copper standard has the advantage that accurate temperature measurement is unnecessary.

\section{THE TEMPERATURE COEFFICIENT MEASUREMENTS}

For the measurements of the temperature coefficient, potential terminals were used: The resulting temperature coefficient is therefore that of "constant mass." (See page 92.) The terminals were soft-soldered to the wires a little over a meter apart. Measurements of the resistance between the meter knife-edges before and after soldering on the potential terminals showed differences in general well below I in ro ooo. Hence it may safely be assumed that the soldering did not appreciably alter the conductivity. The temperature coefficient was measured by comparing the resistance of the sample at two or more temperatures with the resistance of a copper standard in the same bath. This gave the difference between the temperature coefficients of the sample and of the standard, and as the difference was always small the tem- 
perature measurements did not have to be made with great accuracy. The temperatures used in these comparisons were between $20^{\circ} \mathrm{C}$ and $50^{\circ} \mathrm{C}$, the range being always greater than $10^{\circ} \mathrm{C}$. 'The temperature coefficients of all the samples were measured against the same copper standard. The relative accuracy of the resulting values of the temperature coefficient is therefore high and is estimated as within \pm 0.000004 (or O.I per cent).

The absolute accuracy of the temperature coefficient values depends on measurements which were made upon three of the samples, for a range of $12^{\circ} \mathrm{C}$ to $100^{\circ} \mathrm{C}$. The resistances (of two of these) were compared against manganin standards at constant temperature, and the temperatures measured with a mercury thermometer at approximate $10^{\circ}$ intervals in this range. (The third was measured only at $25^{\circ} \mathrm{C}, 55^{\circ} \mathrm{C}$, and $100^{\circ} \mathrm{C}$.) The measurements were made in a well-stirred oil bath. It was ascertained that no appreciable errors were introduced by conduction of heat through the leads of the wire under observation, and that the temperature was sufficiently uniform to permit of accurate temperature measurement. To the thermometer readings were applied calibration, ice point, and emergent stem corrections. The accuracy of the resistance measurements was within 0.004 per cent, and the precision of reading the thermometer was within $0.03^{\circ} \mathrm{C}$. The higher temperatures were not known to this accuracy, however, because of the large correction for emergent stem. Thus at $100^{\circ} \mathrm{C}$ the stem correction was uncertain by $0.2^{\circ} \mathrm{C}$, which makes the computed value of the temperature coefficient uncertain by 0.000 or , or 0.2 per cent. The accuracy of the computed values of the temperature coefficient from the observations below $70^{\circ} \mathrm{C}$ is estimated as within 0.000004 , or o. I per cent; the relative values of the temperature coefficients of the three wires as obtained from these measurements, and as obtained by measurement against the copper standard, agree well within this accuracy. Within the limits of accuracy stated, for the range of $12^{\circ} \mathrm{C}$ to $100^{\circ} \mathrm{C}$, the temperature coefficient was found to be linear. The important range of temperature in commercial work extends to about $75^{\circ} \mathrm{C}$. The temperature coefficient is here shown to be accurately linear up to this temperature, and if there is any departure from a linear relation between $70^{\circ} \mathrm{C}$ and $100^{\circ} \mathrm{C}$ it is inappreciable in commercial work. 
The results of the measurements on the separate samples are given in the table below. In each case $\alpha_{20}$ is divided by the percent conductivity and the quotient given under $\mathrm{C}$. C , the constant resulting, is the computed value of the temperature coefficient of copper of Ioo percent conductivity.

\section{TABLE I}

Temperature Coefficients (1) Observed, and (2) Computed for Copper of 100 Percent Conductivity

\begin{tabular}{|c|c|c|c|c|}
\hline $\begin{array}{l}\text { Percent conduc- } \\
\text { tivity }^{2}\end{array}$ & $\left(\begin{array}{c}\alpha_{20} \\
=\frac{\mathbf{R}_{t}-\mathbf{R}_{20}}{\mathbf{K}_{20}[t-20]}\end{array}\right)$ & 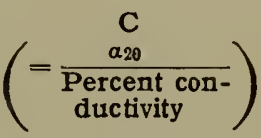 & Mean values of $\mathrm{C}$ & $\begin{array}{l}\text { Deviations from } \\
\text { final mean }\end{array}$ \\
\hline${ }^{3} 97.44$ & $0.00384_{0}$ & $0.00394_{1}$ & & \\
\hline${ }^{2} 97.46$ & $384_{3}$ & $394_{3}$ & & \\
\hline${ }^{3} 97.54$ & $384_{6}$ & $394_{3}$ & & \\
\hline 100.22 & $395_{0}$ & $394_{1}$ & $0.00394_{2}$ & $+0_{4}$ \\
\hline 100.24 & $395_{2}$ & $394_{3}$ & & \\
\hline 100.29 & $395_{4}$ & $394_{3}$ & & \\
\hline 100.44 & $395_{9}$ & $394_{2}$ & & \\
\hline${ }^{3} 97.47$ & $382_{5}$ & $392_{4}$ & & \\
\hline 100.11 & $393_{1}$ & $392_{7}$ & $.00392_{6}$ & $-1_{2}$ \\
\hline 99.96 & $392_{7}$ & $392_{9}$ & & \\
\hline 100.09 & $392_{9}$ & $392_{6}$ & $.00392_{7}$ & $-1_{1}$ \\
\hline${ }^{3} 98.18$ & $38 \sigma_{0}$ & $393_{2}$ & & \\
\hline${ }^{3} 98.25$ & $386_{0}$ & $392_{9}$ & $.00393_{0}$ & $-0_{8}$ \\
\hline 99.73 & $393_{5}$ & $394_{8}$ & & \\
\hline 100.16 & $393_{6}$ & $393_{0}$ & $.00393_{8}$ & 0 \\
\hline${ }^{3} 96.56$ & $380_{6}$ & $394_{2}$ & & \\
\hline${ }^{3} 96.96$ & $382_{8}$ & $394_{8}$ & & \\
\hline 99.63 & $391_{7}$ & $393_{2}$ & $.00393_{7}$ & $-0_{1}$ \\
\hline 99.97 & $392_{7}$ & $392_{8}$ & & \\
\hline${ }^{3} 94.13$ & $371_{6}$ & $394_{8}$ & & \\
\hline${ }^{3} 95.80$ & $378_{2}$ & $394_{8}$ & & \\
\hline 96.60 & $381_{5}$ & $394_{9}$ & $.00394_{9}$ & $+1_{1}$ \\
\hline 99.89 & $394_{6}$ & $395_{0}$ & & \\
\hline${ }^{3} 97.07$ & $384_{0}$ & $395_{5}$ & & \\
\hline 99.75 & $394_{0}$ & $395_{0}$ & $.00395_{2}$ & +1 \\
\hline
\end{tabular}

2 100 percent conduetivity corresponds to resistivity of $0.153022 \mathrm{ohm}$ per meter-gram (or 1.72128 micro-ohms per centimeter cube, density $=8.89$ ), at $20^{\circ} \mathrm{C}$.

'Hard-drawn wires; the others are annealed. 
TABLE I-Continued

\begin{tabular}{|c|c|c|c|c|}
\hline $\begin{array}{l}\text { Percent conduc- } \\
\text { tivity }^{2}\end{array}$ & 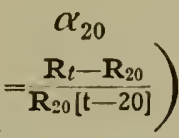 & $\left.=\frac{C}{a_{20}} \begin{array}{c}\text { Percent con- } \\
\text { ductivity }\end{array}\right)$ & Mean values of $\mathrm{C}$ & $\begin{array}{l}\text { Deviations from } \\
\text { final mean }\end{array}$ \\
\hline${ }^{3} 97.96$ & $0.00385_{3}$ & $0.00393_{3}$ & $0.00393_{2}$ & $-0_{6}$ \\
\hline 100.70 & $395_{9}$ & $393_{2}$ & & \\
\hline 99.14 & $392_{6}$ & $396_{0}$ & $.00395_{6}$ & $+1_{8}$ \\
\hline 99.39 & $392_{8}$ & $395_{2}$ & & \\
\hline${ }^{3} 96.95$ & $383_{0}$ & $395_{0}$ & $.00394_{3}$ & $+0_{5}$ \\
\hline 100.26 & $394_{6}$ & $393_{6}$ & & \\
\hline${ }^{3} 97.84$ & $385_{0}$ & $393_{5}$ & $.00393_{2}$ & $-\mathrm{O}_{6}$ \\
\hline 100.54 & $395_{1}$ & $393_{0}$ & & \\
\hline${ }^{3} 97.25$ & $382_{8}$ & $393_{6}$ & $.00393_{4}$ & $-0_{4}$ \\
\hline 100.14 & $393_{8}$ & $393_{3}$ & & \\
\hline${ }^{3} 97.75$ & $384_{5}$ & $393_{3}$ & $.00393_{1}$ & $-0_{7}$ \\
\hline 100.70 & $395_{7}$ & $392_{9}$ & & \\
\hline \multirow{3}{*}{\multicolumn{3}{|c|}{$\begin{array}{l}\text { Final mean } \\
\text { Final mean rounded off }\end{array}$}} & & $\begin{array}{c}\text { Mean devia- } \\
\text { tion }\end{array}$ \\
\hline & & & $.00393_{8}$ & $=0_{8}$ \\
\hline & & & .00394 & $=0.2 \%$ \\
\hline
\end{tabular}

${ }^{3}$ Hard-drawn wires; the others are annealed.

3. THE SOURCES OF MATERIAL REPRESENTED

Each one of the groups into which the results are divided represents one source of material. These sources, without reference to the order in the table, were the following:

Smelters. . . . . . . . . $\left\{\begin{array}{l}\text { Calumet and Hecla Smelting Works, Hubbell, Mich. } \\ \text { Quincy Mining Company, Hancock, Mich. } \\ \text { Buffalo Smelting Works, Buffalo, N. Y. }\end{array}\right.$ Electrolytic refiners........ $\left\{\begin{array}{l}\text { American Smelting and Refining Company, Mau- } \\ \text { rer, N. J. } \\ \text { The Baltimore Copper Smelting and Rolling Com- } \\ \text { pany, Baltimore, Md. } \\ \text { The United States Metals Refining Company } \\ \text { Chrome, N. J. } \\ \text { Raritan Copper Works, Perth Amboy, N. J. } \\ \text { Nichols Copper Company, Laurel Hill, N. Y. } \\ \text { A. Grammont, Pont-de-Chéruy, France. }\end{array}\right.$ $58397^{\circ}-\mathrm{II}-6$ 
Wire manufacturers........ $\left\{\begin{array}{l}\text { American Brass Company, Waterbury, Conn. } \\ \text { John A. Roebling's Sons Company, Trenton, N. J. } \\ \text { Standard Underground Cable Company, Perth } \\ \text { Amboy, N. J. } \\ \text { Heddernheimer Kupferwerk und Süddeutsche } \\ \text { Kabelwerke, Frankfurt-am-Main, Germany. } \\ \text { Kabelfabrik - und Drahtindustrie - Actien - Gesell- } \\ \text { schaft, Vienna, Austria. }\end{array}\right.$

Most of these companies kindly furnished the samples of copper wire at the request of the Bureau of Standards. This opportunity is taken of expressing appreciation for the cooperation of these companies. Some of the refiners were represented only in the samples submitted by one of the wire manufacturers. One sample was from an ordinary purchase of wire.

It will be seen that a considerable number of the most important producers of copper are included in the list. This country, Germany, France, and Austria are represented. As the samples (except three; see next paragraph) were the usual commercial grade of copper that is sold for electrical purposes, and as the range of conductivity of the samples covers thoroughly the range of such copper, it is believed that the results are representative. The third column of the table shows the agreement of the samples from each source. The fourth column shows the agreement of the various sources. The fifth column gives the deviations of the group means from the final mean. The mean deviation is 0.000008 , or 0.2 per cent. The experimental error of the separate measurements is probably not greater than 0.000004 , or 0.1 per cent. However, in view of all the circumstances, the mean deviation is remarkably small, and we are justified in saying that the accuracy of the final mean is probably well within $0.000 \mathrm{or}$.

\section{EFFECT OF CHEMICAL DIFFERENCES OF SAMPLES}

The agreement of $C$ for samples differing in chemical composition is shown throughout the list, and in particular by the seventh group. The samples in this group were of copper refined by smelting. The first three samples of this group are the only ones given in the list which do not represent the usual copper which is sold and accepted for use as electrical conductors. The first is a hard-drawn wire and the third an annealed wire of "cupola" copper, known to be highly arsenical. The second is a hard-drawn 
wire of "silver-bearing" copper, containing o.I7 per cent silver. The fourth in the group is the regular refined copper of the smelter. Chemical analyses of the refined copper and the cupola copper, which were furnished by the smelting company, are given herewith:

\begin{tabular}{|c|c|c|}
\hline & Refined & Cupola \\
\hline 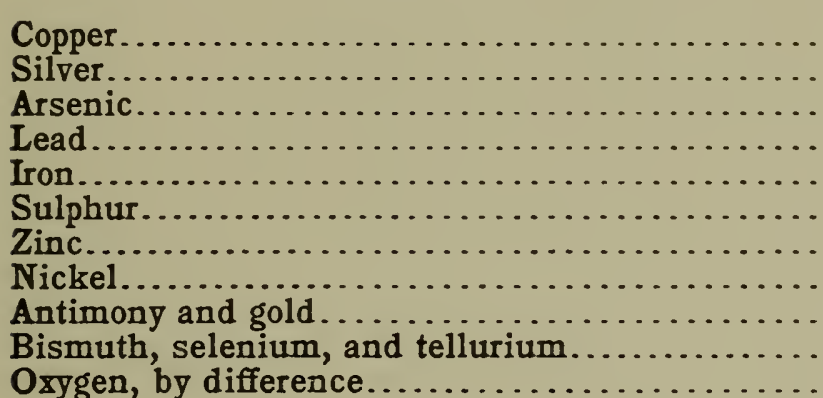 & $\begin{array}{c}99.88 \\
0.0710 \\
.0006 \\
\text { None } \\
.0014 \\
.0022 \\
\text { Trace } \\
.0010 \\
\text { Faint trace } \\
\text { None } \\
.0450\end{array}$ & $\begin{array}{c}99.85 \\
0.0570 \\
.0099 \\
\text { Trace } \\
.0063 \\
.0064 \\
.0008 \\
.0108 \\
\text { Faint trace } \\
\text { None } \\
.0560\end{array}$ \\
\hline
\end{tabular}

The arsenic alone is sufficient to account for the low conductivity of the cupola copper.

\section{EFFECT OF PHYSICAL DIFFERENCES OF SAMPLES}

The agreement of $C$ for samples differing in physical condition is shown by the first, second, sixth, eighth, ninth, eleventh, twelfth, thirteenth, and fourteenth groups. The wires indicated by a superior figure $\left(^{3}\right)$ were hard-drawn; the others were annealed. The effect of hard-drawing and annealing was further tested. A piece of the same soft wire from which was taken the fifth sample in the table was partially hardened by drawing through dies, and the measurements showed

$$
\text { conductivity }=98.96 \%, \alpha_{20}=0.003902, C=0.003943
$$

Also, a piece of the hard-drawn wire given second in the table was annealed by heating electrically to a dull-red heat and gave the following

$$
\text { conductivity }=\text { IOO. } 15 \%, \alpha_{20}=0.003948, C=0.003942
$$

Again, the identical sample given first in the table was annealed, and gave

$$
\text { conductivity }=\text { 100.1 } 4 \%, \alpha_{20}=0.003946, C=0.00394 \mathrm{I}
$$

The agreement of $C$ before and after the alteration of physical condition in all cases is within the experimental error. 


\section{EFFECT OF LOCAL HARDENING}

The effect of local hardening of a wire was also investigated. This is of importance because in ordinary use copper wire is bent and coiled. Bending is known to produce local hardening and increase of resistance. The increase of resistance is usually considered to be due simply to increase of specific resistance, just as the hardening of a wire by drawing increases the specific resistance. It would therefore be expected that the temperature coefficient would increase as does the resistance. That this view is in error was shown by the following experiments. An annealed wire was bent back and forth at a number of points, and the resistance and temperature coefficient remeasured. The apparent conductivity decreased, while the temperature coefficient scarcely changed at all. The wire was then annealed and remeasured. The results are given in the following table:

\begin{tabular}{l|r|r|r}
\hline & Percent conductivity & \multicolumn{1}{c|}{$\alpha_{20}$} & \multicolumn{1}{c}{$\mathrm{c}$} \\
\hline Before bending & 100.11 & 0.003931 & 0.003927 \\
After bending & 99.31 & .003926 & $\ldots \ldots \ldots \ldots \ldots \ldots \ldots$ \\
After annealing & 99.48 & .003929 & $\ldots \ldots \ldots \ldots \ldots$ \\
\hline
\end{tabular}

Another annealed wire was treated more severely, bent, pulled, twisted. The results are given in the following table:

\begin{tabular}{l|c|c|c}
\hline & Percent conductivity & \multicolumn{1}{c|}{$\alpha_{20}$} & \multicolumn{1}{c}{$\mathrm{C}$} \\
\hline Before distortion & 100.44 & 0.003959 & 0.003942 \\
After distortion & 98.35 & .003931 & $\ldots \ldots \ldots \ldots \ldots \ldots \ldots$ \\
After annealing & 98.90 & .003953 & $\ldots \ldots \ldots \ldots \ldots$ \\
\hline
\end{tabular}

In this case the apparent conductivity showed a large decrease upon distortion, and the temperature coefficient a slight decrease. We therefore conclude that most of the apparent decrease in conductivity is due to some such cause as change of cross section. This conclusion is strengthened by the result of the annealing. If the decrease in conductivity were due simply to a hardening, we 
should expect that the annealing would restore the former conductivity. But we see that the annealing actually raises the apparent conductivity only slightly and raises the temperature coefficient a proportionate amount, in fact restoring practically the original temperature coefficient. The greater part of the decrease in apparent conductivity, due to local distortions, is therefore, caused by local changes in cross section. Ordinary bending, as seen from the first of these two wires, changes the temperature coefficient practically not at all. It will be noticed that the value of $C$ is not computed for the distorted wires in the two preceding tabulations. This is to emphasize the fact that a correct value of $C$ is not obtained with samples which have been bent and distorted; as may be seen, in these cases the value of $C$ would be too high. In the measurement of conductivity the assumption of a uniform sample must be carefully guarded, while this is not necessary in the measurement of temperature coefficient. This will be discussed below.

\section{COPPER SAMPLES THAT HAD NEVER BEEN MELTED}

Besides the results already given, measurements were made upon some samples of electrolytic copper wire drawn directly from cathode plates without intermediate melting. These were of especially high conductivity because of high purity, the chief gain in conductivity probably being due to freedom from the cuprous oxide introduced in melting. The results were:

\begin{tabular}{c|c|c}
\hline Percent conductivity & $\alpha_{20}$ & $\mathrm{C}$ \\
\hline 101.33 & 0.003972 & 0.003920 \\
101.35 & .003969 & .003916 \\
101.50 & .003976 & .003917 \\
499.46 & .003896 & .003917 \\
\hline
\end{tabular}

Hard-drawn.

The first two samples were from one of the electrolytic refiners mentioned above, and the third and fourth from another; the first three samples were annealed, the fourth was hard drawn. These results for $C$ lie slightly below any of the values in the table above. 
They were omitted from the table because this cathode copper was specially prepared for experimental purposes, and the table is intended to represent simply the copper commercially obtainable. Further, there is evidence that wires prepared from the cathode plates are not as homogeneous as the ordinary copper. Thus some of the wires had a longitudinal black line the whole length of the wire. This appeared to be the result of a creasing over of the surface layer by the hammering process which was used to prepare the plates for drawing; the surface layer probably contained iron and oxide and other impurities. The view that the low values of $C$ are due to inhomogeneities which are not present in the ordinary copper which has been melted is strengthened by a further experiment. The samples were annealed at a dull red heat; the results then were:

\begin{tabular}{c|c|c}
\hline Percent conductivity & $\alpha_{20}$ & $\mathrm{C}$ \\
\hline 101.39 & 0.003982 & 0.003927 \\
101.54 & .003983 & .003922 \\
101.53 & .003984 & .003924 \\
101.41 & .003980 & .003925 \\
\hline
\end{tabular}

Cathode copper is known to occlude considerable quantities of hydrogen. ${ }^{5}$ We might, therefore, expect abnormalities in its properties. The precise explanation of the original low values for $C$ is not, however, apparent; if there were defects in these wires in the nature of local discontinuities we should expect the apparent conductivity to be less than the real conductivity, and the temperature coefficient to be unaffected; hence the value of $C$ would be too high.

Another anomalous case found was that of some native lake copper which had never been melted down. The wires had been drawn directly from the mass of native copper. Annealed, it had higher conductivity and temperature coefficient than any other copper as yet measured at the Bureau of Standards (except that

${ }^{5}$ Soret-Comptes Rendus 107, p. 733; 1888, and 108, p. 1298; 1889. Foerster-ZS Electrochem. 5, p. 508; 1899. 
the temperature coefficient of the above-mentioned cathode copper was higher after re-annealing). The results follow; the first is a hard-drawn wire, the second annealed.

\begin{tabular}{|c|c|c|}
\hline Percent conductivity & $\alpha_{20}$ & $\mathrm{C}$ \\
\hline 99.17 & 0.003885 & 0.003918 \\
\hline 101.71 & .003978 & .003911 \\
\hline
\end{tabular}

It is to be noted that both these wires and the cathode samples of the preceding paragraph were prepared from copper that had not been melted.

\section{CONCLUSIONS}

\section{PROPORTIONALITY OF TEMPERATURE COEFFICIENT AND CONDUCTIVITY}

The principal result of this investigation may be expressed in the form of the following practical rule: The $20^{\circ} \mathrm{C}$ temperature coefficient of a sample of copper is given by multiplying the number expressing the percent conductivity by 0.00394. (I00 percent conductivity is taken as corresponding to a resistivity of 0.153022 ohm per meter-gram at $20^{\circ} \mathrm{C}$.) This is intended to apply merely to the copper furnished for electrical uses, and to the temperature range of $10^{\circ} \mathrm{C}$ to $100^{\circ} \mathrm{C}$, over which the temperature coefficient was found to be linear. The practical importance of this relation is evident, for it gives the temperature coefficient of any sample when the conductivity is known. Thus, the temperature coefficient for the range of conductivity of commercial copper may be exhibited by the following table:

TABLE II.

Temperature Coefficients of Commercial Copper

$R_{\mathbf{t}}=\mathbf{R}_{\mathbf{t}_{1}}\left(1+a_{\mathbf{t}_{1}}\left[t-t_{1}\right]\right)$

\begin{tabular}{c|c|c|c|c|c}
\hline $\begin{array}{c}\text { Ohms per meter- } \\
\text { gram at 20 }\end{array}$ & $\begin{array}{c}\text { Percent con- } \\
\text { ductivity }\end{array}$ & \multicolumn{1}{|c|}{$\alpha_{0}$} & \multicolumn{1}{|c|}{$\alpha_{25}$} & \multicolumn{1}{|c|}{$\alpha_{20}$} & \multicolumn{1}{c}{$\alpha_{25}$} \\
\cline { 1 - 4 } 0.15940 & $96 \%$ & 0.00409 & 0.00386 & 0.00378 & 0.00371 \\
.15776 & 97 & .00414 & .00390 & .00382 & .00375 \\
.15614 & 98 & .00418 & .00394 & .00386 & .00379 \\
.15457 & 99 & .00423 & .00398 & .00390 & .00383 \\
.153022 & 100 & .00428 & .00402 & .00394 & .00386 \\
.15151 & 101 & .00432 & .00406 & .00398 & .00390 \\
\hline
\end{tabular}


The above table was calculated by means of the following formula, which holds for any temperature, $t_{1}$, and any percent conductivity, $n$ (expressed decimally-e. g., if percent conductivity $=99$ per cent, $n=0.99)$ :

$$
\alpha_{t_{1}}=\frac{1}{\frac{1}{n(.00394)}+\left(t_{1}-20\right)}
$$

\section{THE RESISTIVITY-TEMPERATURE CONSTANT}

Conductivity tests are made in connection with the purchase of wire by many refiners, wire manufacturers, makers of instruments, and others. A knowledge of the temperature coefficient is important in the determination of conductivity when the measurements are made at a temperature other than the standard temperature. Our rule can be put in a remarkably convenient form for such cases, viz: The change of the resistivity per degree $C$ of a sample of copper is $0.000598 \mathrm{ohm}$ per meter-gram, or $0.0068 \mathrm{I}$ micro-ohm per centimeter cube. Accordingly the resistivity as found at any temperature may be reduced to standard temperature simply by adding one of these constants multiplied by the temperature difference. These constants are independent both of the temperature of reference and of observation, and also independent of the sample of copper.

\section{TEMPERATURE CORRECTION FOR MEASUREMENTS AGAINST A COPPER STANDARD}

When a determination of conductivity involves a resistance measurement against a copper standard at the same temperature as the test sample, usually no temperature correction is necessary. When, however, an accuracy of o.or per cent is striven for, it is often necessary to make a correction. In such cases the metergram resistivity at the standard temperature, $T$, is obtained by adding to the meter-gram resistivity as calculated from the resistance comparison at $t^{\circ}$, the quantity $\left[(t-T)\left(\delta-\delta_{n}\right)(0.0039)\right]$; in which $\delta=$ meter-gram resistivity of the sample and $\delta_{\mathrm{n}}=$ quotient of 0.000598 by the temperature coefficient of the copper standard. Similarly the centimeter cube resistivity at the standard temperature is obtained by adding to the centimeter cube 
resistivity as calculated from the resistance comparison at $t^{\circ}$, the quantity $\left[(t-T)\left(\rho-\rho_{\mathrm{n}}\right)(0.0039)\right]$; in which $\rho=$ centimeter cube resistivity of the sample and $\rho_{\mathrm{n}}=$ quotient of $0.0068 \mathrm{I}$ by the temperature coefficient of the copper standard.

\section{EFFECT OF HARDENING, IMPURITIES, AND DISTORTION ON THE TEMPERATURE COEFFICIENT}

A conclusion which follows from the results is that the resistance added to that of pure copper by hardening or by the presence of the small quantities of impurities usually found in refined copper has no temperature coefficient. That is, when the resistance of a piece of copper is changed by the addition of small quantities of impurities or by hardening, the absolute change of resistance with temperature is unaffected, while the percentage change of resistance with temperature is affected. On the other hand, when the resistance is changed by an alteration of dimensions the absolute change of resistance with temperature is affected and the percentage change of resistance with temperature is not. From the latter fact. may be drawn a practical conclusion concerning the local hardening and distortion of a wire. As shown above, the ordinary coiling, winding, and bending of a wire may increase its resistance. In such cases there are local changes of dimensions which are much more effective in changing the resistance than the slight hardening caused, and thus such distortions do not materially affect the percentage temperature coefficient. It may therefore be assumed without serious error that the temperature coefficient of a copper wire is the same after winding on a machine or instrument as it was before. Accordingly, if a measurement has been made of either the conductivity or the temperature coefficient of the wire before winding the temperature coefficient may safely be assumed to be known after winding and may be used in the calculation of temperature rise.

Although the agreement of the values for $C$ indicates that it is a real constant for copper, there are still variations from the mean greater than the experimental error. The higher values of $C$ are possibly explainable on the basis of local distortions of the samples, which would give wrong values for the conductivity, as above. 
The lower values, particularly those for the cathode copper and for the native lake copper, are not explained. Perhaps all the variations are due to differences in the treatment of the metal, or to the varying effect of the different chemical impurities upon the conductivity and temperature coefficient.

\section{THE TEMPERATURE COEFFICIENT AS A MEASUREMENT OF CONDUCTIVITY}

The relation between conductivity and temperature coefficient emphasizes the desirability of making a conductivity test on samples used instead of assuming values. It also indicates, however, that the conductivity test can be replaced by a measurement of the temperature coefficient. It is often easier to measure the resistance between two fixed points on a sample at two known temperatures and thus obtain the temperature coefficient than to measure the specific resistance, which is in a sense an absolute measurement. A value can thus be obtained for the conductivity which is reliable, according to the present results, within one-half per cent. Four particular cases suggest themselves in which the measurement of temperature coefficient has considerable advantage over a conductivity measurement.

(a) Odd shapes.-Unless a uniform sample can be prepared, the determination of conductivity directly is hopeless. Through the temperature coefficient, the conductivity may be known for a specimen of any shape, without the danger of altering its properties by the preparation of a uniform sample.

(b) Short samples.-For very short samples, the difficulty of measurement of the dimensions and the possible uncertainty of the current distribution limit the use of conductivity measurement. Neither objection applies to the determination of the temperature coefficient.

(c) Wires that have been distorted or bent.-As shown above, the apparent conductivity of a wire that has once been distorted by bending is incorrect, while such treatment does not materially affect the temperature coefficient or the real conductivity. The temperature coefficient, therefore, gives the real conductivity better in such cases than does a direct measurement of the conductivity. 
(d) The estimation of chemical purity.-The use of conductivity as a criterion of chemical purity is familiar. Evidently the temperature coefficient is fully as reliable a criterion as the conductivity, and is more generally applicable, and is often an easier test to apply than either the conductivity or chemical determinations. Indeed, the temperature coefficient is used as a criterion of purity in the selection of platinum for platinum thermometers. It is also interesting to know that the temperature coefficient is used commercially as a criterion of purity for some of the metals used in incandescent lamp manufacture; it is the most delicate test available of some of the desirable properties of the pure material, surpassing even the chemical tests, which are much more laborious.

\section{EXPLANATION OF DISAGREEMENTS OF PREVIOUS OBSERVERS}

We now have an explanation of the disagreements of the results of previous observers, aside from the errors of their measurements. For example, one of the most carefully established previous values, that adopted by the American Institute of Electrical Engineers, was the result of over roo determinations made by Messrs. Robinson and Holz, of the General Electric Company. They found variations in the value and considered 0.0042 as the best that could be done in assigning a mean. As may be seen, the same conclusion could be reached from the data of this paper if the temperature coefficient only were considered. 0.0042 is the temperature coefficient, $\alpha_{0}$, for copper of conductivity equal to 98.3 per cent. If it is used for a sample whose conductivity is roo per cent, the error of the computed value at $100^{\circ} \mathrm{C}$ is over one-half per cent. (If the French coefficient is used in a similar case, the error is 2 per cent.) It is interesting to notice that the A. I. E. E. temperature coefficient happens to correspond very closely to 98 percent conductivity, which has been the conductivity usually specified for annealed copper on purchases in this country. 
7. VALUES SUGGESTED FOR ANNEALED AND HARD-DRAWN COPPER

According to the results of an investigation now being carried out at the Bureau of Standards, a fair value to assume for the conductivity of good commercial annealed copper wire (in cases where assumption is unavoidable) is Ioo per cent, for which

$$
\alpha_{0}=0.00428, \alpha_{15}=0.00402, \alpha_{20}=0.00394 \text {, and } \alpha_{25}=0.00386
$$

This value would usually apply to instruments and machines, since they are generally wound with annealed wire. Similarly, the conductivity of good commercial hard-drawn copper wire may be taken as 97.3 per cent, for which

$$
\alpha_{0}=0.004 \text { I } 5, \alpha_{15}=0.0039 \text { I }, \alpha_{20}=0.00383 \text {, and } \alpha_{25}=0.00376
$$

\section{THE MATHEMATICAL EXPRESSION OF THE TEMPERATURE COEFFICIENT}

The simple mathematical relations between the different methods of expressing the temperature coefficient are sometimes confused; it is therefore thought desirable to include a discussion of them in this paper.

\section{ON GENERAL FUNCTIONS OF TEMPERATURE}

The law expressing any variation with temperature may be written:

$$
R_{t}=R_{\mathrm{r}} f(t)
$$

in which $R_{r}$ is a constant, $T$ being some standard temperature. The "temperature coefficient at $t_{1}{ }^{\circ}, " \alpha_{t_{1}}$, is defined in the most general way by the following equation:

$$
\alpha_{t_{1}}=\frac{\mathrm{I}}{R_{t_{1}}}\left(\frac{d R}{d t}\right)_{t_{1}}
$$

This equation applies to any variation with temperature, whether linear or not.

From (I) and (2).

$$
\alpha_{t_{1}}=\frac{\mathbf{I}}{f\left(t_{1}\right)}\left[\frac{d f(t)}{d t}\right]_{t_{1}}
$$


Hence, if we know $f(t)$, we can calculate the temperature coefficient at any temperature. $f(t)$ can usually be put in the form of a series of ascending powers of $t$, so that the calculation of $\alpha_{t_{1}}$ is simple. This quantity, $\alpha_{t_{1}}$ is then usable in calculating the value of $\mathrm{R}$ for temperatures close to the temperature of reference, $t_{1}$, (and is not, in the general case, applicable to temperatures far from $t_{1}$ ). Thus, from (2),

$$
(d R)_{t_{1}}=\alpha_{t_{1}} R_{t_{1}} d t
$$

Hence, for $t$ not far from $t_{1}\left\{\begin{aligned} R_{t}-R_{t_{1}} & =\alpha_{t_{1}} R_{t_{1}}\left[t-t_{1}\right] \\ R_{t} & =R_{t_{1}}\left(\mathrm{I}+\alpha_{t_{1}}\left[t-t_{1}\right]\right)\end{aligned}\right.$

(6) and (3) enable us to apply a simple linear computation to any variation with temperature for small temperature differences.

Case I. Linear temperature coefficient.-The law of variation with temperature is

or,

$$
\begin{gathered}
R_{t}=R_{0}\left(\mathrm{I}+\alpha_{0} t\right) \\
f(t)=\mathrm{I}+\alpha_{0} t
\end{gathered}
$$

Hence, from (3) and (8),

$$
\begin{aligned}
& \alpha_{t_{1}}=\frac{\alpha_{0}}{\mathrm{I}+\alpha_{0} t_{1}}, \text { or, } \\
& \alpha_{t_{1}}=\frac{\mathrm{I}}{\frac{\mathrm{I}}{\alpha_{0}}+t_{1}}
\end{aligned}
$$

Now, since $\frac{d R}{d t}=$ constant $=\frac{R_{t}-R_{t_{2}}}{t-t_{2}}$

$\therefore$ from (2)

$$
\begin{aligned}
& \alpha_{t_{2}} R_{t_{2}}=\frac{R_{t}-R_{t_{2}}}{t-t_{2}} \\
& \therefore R_{t}=R_{t_{2}}\left(\mathrm{I}+\alpha_{t_{2}}\left[t-t_{2}\right]\right)
\end{aligned}
$$

It is to be noted that (II) is the same as (6), except that (II) has not the restriction that $t$ be not far from $t_{1}$. We see from (II) 
that any temperature may be used as standard temperature ${ }^{\circ}$ as well as $0^{\circ}$ [as in (7)], and still the form of $f(t)$ be unchanged. Thus, corresponding to (IO), we have

$$
\alpha_{t_{1}}=\frac{\mathrm{I}}{\frac{\mathrm{I}}{\alpha_{t 2}}+\left(t_{1}-t_{2}\right)},
$$

by means of which we can obtain the ture coefficient attempera any temperature directly from its value at any other temperature.

It is sometimes convenient to use (I2) in the form

$$
\alpha_{t_{1}}=\alpha_{t_{2}}-\alpha_{t_{2}}^{2}\left(t_{1}-t_{2}\right)+\alpha_{t_{2}}^{3}\left(t_{1}-t_{2}\right)^{2}-. . .
$$

The temperature coefficient of resistance of copper is linear within practical limits of accuracy and of temperature, and the above formulas apply to it. As has been shown in this paper, the temperature coefficient varies for different samples of copper, and a relation of temperature coefficient to conductivity has been found. We may now write a formula giving the temperature coefficient for a sample of copper of any conductivity and at any temperature of reference. Denoting percent conductivity, expressed decimally, by $\mathrm{n}$, our experimental result is

$$
\begin{aligned}
\alpha_{20} & =n(0.00394) \\
\therefore \quad \alpha_{t_{1}} & =\frac{\mathrm{I}}{\frac{\mathrm{I}}{n(0.00394)}+\left(t_{1}-20\right)}
\end{aligned}
$$

The table given on page $8 \mathrm{I}$ was calculated by (I5). As pointed out on page 82 , the change of resistivity per degree change of temperature is independent of the temperature of reference and of the sample of copper. Hence, for reducing resistivity from one temperature to another no formulas are needed. Formulas (14) and (I5) are, of course, intended to apply only to the kinds of copper and the temperature range of this paper and are believed to be reliable within one-half per cent.

"The terms should not be confused: "Temperature of reference" $=t_{1}=$ temperature at which we compute a temperature coefficient. "Standard temperature" $=\mathrm{T}=$ temperature in terms of which $\mathrm{f}(\mathrm{t})$ is expressed, Eq. ( $\mathrm{I}$ ). 
Case II. Two-term temperature formula.-This is the case of many resistance materials, of which manganin is an important example. The law of variation with temperature may be written:

or,

$$
R_{t}=R_{T}\left(\mathrm{I}+a_{T}[t-T]+b_{T}[t-T]^{2}\right)
$$

$$
f(t)=\mathrm{I}+a_{T}[t-T]+b_{T}[t-T]^{2}
$$

From (3) and (1 7),

$$
\alpha_{t_{1}}=\frac{a_{T}+2 b_{T}\left[t_{1}-T\right]}{\mathrm{I}+a_{T}\left[t_{1}-T\right]+b_{T}\left[t_{1}-T\right]^{2}}
$$

In the case of manganin, $a$ and $b$ are very small quantities, $a_{25}$ being usually between $-0.000 \mathrm{or}$ and $+0.000 \mathrm{O} 3$, and $b$ between -0.0000003 and -0.0000005 ; hence we may neglect the denominator in (I8) and write

$$
\alpha_{t_{1}}=a_{T}+2 b_{T}\left(t_{1}-T\right)
$$

Also,

$$
\alpha_{t_{1}}=\alpha_{t_{2}}+2 b_{T}\left(t_{1}-t_{2}\right)
$$

By means of (20) we can obtain the temperature coefficient at any temperature directly from its value at any other temperature.

Case III. Reciprocal two-term formula.-This is the case of Matthiessen's formula for the temperature coefficient of copper. The law of variation with temperature is:

$$
\frac{R_{t}}{R_{0}}=\frac{\mathrm{I}}{\mathrm{I}+A t+B t^{2}}
$$

or

From (3) and (22),

$$
f(t)=\frac{\mathrm{I}}{\mathrm{I}+A t+B t^{2}}
$$

$$
\alpha_{t_{1}}=\frac{-A-2 B t_{1}}{. \mathrm{I}+A t_{1}+B t_{1}^{2}}
$$

The values of A and B in Matthiessen's formula for copper are -0.0038701 and +0.000009009 , respectively. Substituting these values in (23), we find for $\alpha_{0}$ and $\alpha_{20}$ :

$$
\alpha_{0}=+0.003870, \alpha_{20}=+0.003789
$$


"Matthiessen's temperature coefficient for $0^{\circ}$ to $20^{\circ}$," as given on page 70 , is quite a different thing from the temperature coefficient at a given temperature, as above discussed. The value there considered (page 70) is simply:

$$
\begin{aligned}
& \alpha(\text { o to } 20)_{0}=\frac{R_{20}-R_{0}}{20 R_{0}}=\frac{\frac{R_{20}}{R_{0}}-\mathrm{I}}{20}=+0.003984 \\
& \alpha(\text { o to } 20)_{20}=\frac{R_{20}-R_{0}}{20 R_{20}}=\frac{\mathrm{I}-\frac{R_{0}}{R_{20}}}{20}=+0.003690
\end{aligned}
$$

This pair of values simply reduces from $0^{\circ} \mathrm{C}$ to $20^{\circ} \mathrm{C}$ and from $20^{\circ}$ $\mathrm{C}$ to $0^{\circ} \mathrm{C}$ and applies to no other temperature interval. Not only is the use of this temperature coefficient thus restricted, but the temperature coefficient at particular temperatures, as calculated in (24), is restricted to infinitesimal temperature differences; accordingly we see that it is impossible to use Matthiessen's formula in general without employing the awkward form in which it is expressed.

2. CALCULATION OF IINEAR TEMPERATURE COEFFICIENT FROM OBSERVATIONS

$\alpha_{t_{1}}$ from observations at $t_{1}$ and one other temperature, $t$. From (II),

$$
\alpha_{t_{1}}=\frac{R_{t}-R_{t_{1}}}{R_{t_{1}}\left(t-t_{1}\right)}
$$

$\alpha_{t_{1}}$ from observations at any two temperatures, $t$ and $s$. Applying (25), we deduce

$$
\alpha_{t_{1}}=\frac{R_{t}-R_{s}}{R_{s}\left(t-t_{1}\right)-R_{t}\left(s-t_{1}\right)}
$$

"Differential $\alpha_{t_{1}}$ " from observations at $t_{1}$ and one other temperature, $t$. The "differential $\alpha_{t_{1}}$ " is the temperature coefficient obtained when a copper sample is measured against another in the same bath and thus undergoing the same variations of temperature. It is simply the difference of the temperature coeffi- 
cients of the two samples. Thus, using $\alpha^{\prime}$ and $R^{\prime}$ for one sample, and $\alpha$ and $R$ for the other,

$$
\alpha_{t_{1}}^{\prime}-\alpha_{t_{1}}=\frac{R^{\prime}{ }_{t}-R_{t_{1}}^{\prime}}{R_{t_{1}}^{\prime}-\left(t-t_{1}\right)}-\frac{R_{t}-R_{t_{1}}}{R_{t_{1}}\left(t-t_{1}\right)}=\frac{\frac{R^{\prime}{ }_{t}}{R_{t}}-\frac{R_{t_{t_{1}}}}{R_{t_{1}}}}{\frac{R_{t_{t_{3}}}}{R_{t_{1}}}\left(t-t_{1}\right)}
$$

Let $r$ denote the quantity $\frac{R^{\prime}}{R}$, which is measured in each case.

$$
\therefore \alpha^{\prime}{ }_{t_{1}}-\alpha_{t_{1}}=\frac{r_{t}-r_{t_{1}}}{r_{t_{1}}\left(t-t_{1}\right)}
$$

"Differential $\alpha_{t_{1}}$ " from observations at any two temperatures, $t$ and $s$. When $\alpha^{\prime}{ }_{t_{1}}$ and $\alpha_{t_{1}}$ are nearly the same, as is the case with samples of refined copper, the following approximation applies, deduced from (26),

$$
\alpha_{t_{1}}^{\prime}-\alpha_{t_{1}}=\frac{r_{t}-r_{s}}{r_{s}(t-s)}
$$

[The differential method of determining temperature coefficients is applicable to any form of temperature variation. Applied to the measurement of the temperature coefficients of manganin resistance standards, it has been in use for several years at the Bureau of Standards. The computations are facilitated by the fact that the observed resistance changes are small, and only a low accuracy is required in the measurement of temperature.]

3. EFFECT OF THERMAL EXPANSION IN THE EXPRESSION OF THE LINEAR TEMPERATURE COEFFICIENT

The temperature coefficient of resistance is measured by observations of resistance and temperature. Since the dimensions change with temperature, evidently the temperature coefficient of resistivity or specific resistance can not be directly obtained. As it is sometimes desirable to express these temperature coefficients, the relations are given here.

The temperature coefficient considered up to this point is that ordinarily used; it is the temperature coefficient of resistance as $58397^{\circ}-\mathrm{II}-7^{*}$ 
measured between potential terminals rigidly attached to the wire (such as the soldered terminals used in the work of this paper). It may be defined by Eq. (7), viz:

$$
R_{t}=R_{0}\left(\mathrm{I}+\alpha_{0} t\right)
$$

and may be called the "constant mass" temperature coefficient of resistance.

We shall now use a new set of subscripts for $\alpha$, using $\mathrm{O}^{\circ}$ as the standard temperature throughout. Let:

$\alpha_{\mathrm{R}}=$ "constant mass" temperature coefficient of resistance.

$\alpha_{p}=$ "constant volume" temperature coefficient of resistivity.

$\alpha_{\delta}=$ temperature coefficient of meter-gram resistivity.

$\alpha_{\mathrm{K}}=$ "knife-edge" temperature coefficient of resistance.

1 = length.

$\mathrm{s}=$ sectional area.

$\rho=$ resistance per $\mathrm{cm}$ cube $=\frac{\mathrm{Rs}}{\mathrm{l}}$

$\mathrm{m}=$ mass

$\delta=$ resistance per meter-gram $=\frac{\mathrm{Rm}}{\mathrm{IO} \mathrm{OOOl}^{2}}$

$\gamma=$ coefficient of linear expansion.

Rewriting (7), which defines the "constant mass" temperature coefficient of resistance,

$$
R_{t}=R_{o}\left(\mathrm{I}+\alpha_{\mathrm{R}} t\right)
$$

The "constant volume" temperature coefficient of resistivity may be defined by:

$$
\rho_{t}=\rho_{o}\left(\mathrm{I}+\alpha_{\rho} t\right)
$$

Now,

$$
R_{t}=\frac{\rho_{t} l_{t}}{s_{t}}=\rho_{o}\left(\mathrm{I}+\alpha_{\rho} t\right) \frac{l_{t}}{s_{t}}=\frac{\rho_{o} l_{o}}{s_{o}}\left(\mathrm{I}+\alpha_{\rho} t\right)\left(\mathrm{I}-\gamma_{w} t\right)
$$

where $\gamma_{w}$ is the coefficient of linear expansion of the wire. Since $\gamma$ is a very small quantity we may write:

From (29) and (3I),

$$
R_{t}=R_{o}\left(\mathrm{I}+\left[\alpha_{\rho}-\gamma_{w}\right] t\right)
$$

$$
\alpha_{R}=\alpha_{p}-\gamma_{w}
$$


The temperature coefficient of meter-gram resistivity may be defined by:

$$
\delta_{t}=\delta_{0}\left(\mathrm{I}+\alpha_{j} t\right)
$$

Now, $\quad R_{t}=\frac{I 0 \text { ooo } \delta_{t} l_{t}^{2}}{m}=\frac{I O O O O \delta_{o} l_{o}^{2}}{m}\left(\mathrm{I}+r_{j} t\right)\left(\mathrm{I}+2 \gamma_{w} t\right)$

From (29) and (34),

$$
\therefore R_{t}=R_{o}\left(\mathrm{I}+\left[\gamma_{\gamma}+2 \gamma_{w}\right] t\right)
$$

$$
\alpha_{R}=\alpha_{\delta}+2 \gamma_{w}
$$

The "knife-edge" temperature coefficient of resistance, $\alpha_{\mathrm{K}}$, is that measured between knife-edges mounted on some support. The result obtained depends on the material of the support. $\alpha_{\mathrm{g}}$ is therefore not a true property of the metal, but the difference is very small. $\quad \alpha_{\mathrm{K}}$ may be defined by the following equation, $l$ representing length in terms of the distance between the knife edges.

$$
\left(\frac{R}{l}\right)_{l}=\left(\frac{R}{l}\right)_{0}\left(I+\alpha_{K} t\right)
$$

Now, $\quad R_{t}=\left(\frac{R}{l}\right) l_{l}=\left(\frac{R}{l}\right){ }_{0} l_{o}\left(\mathrm{I}+\alpha_{K} t\right)\left(\mathrm{I}+\left[\gamma_{w}-\gamma_{b}\right] t\right)$,

where $\gamma_{b}$ is the coefficient of linear expansion of the base which supports the knife edges.

$$
\therefore R_{t}=R_{o}\left(\mathrm{I}+\left[\alpha_{K}+\gamma_{w}-\gamma_{b}\right] t\right)
$$

From (29) and (37),

$$
\alpha_{\mathrm{R}}=\alpha_{\mathrm{K}}+\gamma_{\mathrm{w}}-\gamma_{\mathrm{b}}
$$

If the base which supports the knife edges is made of the same metal as the wire under observation, (38) becomes

$$
\alpha_{\mathrm{R}}=\alpha_{\mathrm{K}}
$$

If the base is made of some material whose length does not change with temperature, such as invar, $\left(3^{8}\right)$ becomes

$$
\alpha_{\mathrm{R}}=\alpha_{\mathrm{K}}+\gamma_{\mathrm{w}}
$$


These values of $\alpha_{\mathrm{K}}$ and $\alpha_{\mathrm{R}}$ are intermediate between the values of $\alpha_{\rho}$ and $\alpha_{\hat{\delta}} . \quad \alpha_{\mathrm{R}}$ and $\alpha_{\mathrm{K}}$ are quantities which can be directly measured; $\alpha_{\rho}$ and $\alpha_{\delta}$ are calculated from one of them. The four values are defined in (29), (30), (33), and (36), and their interrelations are given in (32), (35), and (38).

The four $\alpha$ 's are identical for most practical purposes; e. g., for an $\alpha_{\mathrm{R}}$ of copper equal to $0.00428, \alpha_{\hat{\delta}}$ (which is the $\alpha$ farthest different from $\left.\alpha_{\mathrm{R}}\right)=0.00425$. These differences in the $\alpha$ 's are very much less than the variations among different samples and different temperatures of reference. When precision work requires that one of the four $\alpha$ 's be specified, the Bureau of Standards prefers the use of $\alpha_{R}$, which is that directly measured when soldered potential terminals are used, and most nearly corresponds to practical use.

\section{SUMMARY}

I. The foregoing investigation shows that, for representative samples of the copper at present furnished for electrical use, the conductivity and temperature coefficient are proportional, to a high degree of accuracy for differences in physical condition, and to a fair accuracy for differences in chemical composition of samples.

2. This relation may be put in the following very convenient form for reducing the results of resistivity measurements to a standard temperature: The change of the resistivity per degree $C$ of a sample of copper is $0.000598 \mathrm{ohm}$ per meter-gram, or $0.0068 \mathrm{I}$ micro-ohm per centimeter cube.

3. The distortions caused by bending and winding a wire are shown to produce no material change in the temperature coefficient; so that the temperature rise in machines and instruments may be calculated from measurements of the resistance of the windings with greater confidence than heretofore.

4. The measurement of temperature coefficient is shown to present an advantageous substitute for the direct measurement of conductivity in a number of cases.

5. A discussion is given of the mathematical relations between the different methods of expressing the temperature coefficient.

WASHINGTON, July I 2, I 9 IO. 


\section{APPENDIX.-REICHSANSTALT RESULTS}

The bureau has just received from Doctor Warburg, president of the Physikalisch-Technische Reichsanstalt, Germany, a table of results on resistivity and temperature coefficient of copper samples. This table was prepared by Professor Lindeck in February, I910, but has not been published. These results furnish a remarkable corroboration of those obtained here, and permission has been kindly given to publish them herewith. They represent measurements made over a period of five years on various forms of copper samples. They are of especial interest, as they include a great range of conductivity. The table is given below, Table III. The results have also been reduced to the same form of expression as the preceding data of this paper, and as thus reduced are given in Table IV, in the same order as in Table III.

\section{TABLE III}

Results obtained on the resistivity and temperature coefficient of copper at the Reichsanstalt

\begin{tabular}{|c|c|c|c|c|c|c|}
\hline $\begin{array}{c}\text { Resistance test } \\
\text { No. }\end{array}$ & $\begin{array}{c}\text { Form of } \\
\text { specimen } \\
\text { (W=wire) } \\
(\mathrm{W}=\text { sheet) } \\
(\mathrm{T}=\text { trolley }) \\
(\mathrm{C}=\text { cable })\end{array}$ & $\begin{array}{l}\text { Cross section } \\
\text { in } \mathrm{sq} . \mathrm{mm} \text {. }\end{array}$ & $\begin{array}{c}\text { Density, } \\
\text { d }\end{array}$ & $\begin{array}{c}\text { Temperature } \\
\text { coefficient at } \\
15^{\circ} \mathrm{C} \\
\alpha_{15}\end{array}$ & $\begin{array}{c}\text { Specific } \\
\text { resistance; } \\
\text { ohm, meter, } \\
\text { sq.mm. at } 15^{\circ} \mathrm{C} \text {, } \\
\rho^{\prime}{ }_{15}\end{array}$ & $\begin{array}{c}\text { Product } \\
\left(\alpha_{15}\right)\left(\rho^{\prime} 15\right)(10)^{2}\end{array}$ \\
\hline \multirow[t]{2}{*}{$1-1905$} & C 12 & 40. & 8.900 & 0.00400 & $0.0168_{7}$ & 675 \\
\hline & C 19 & 40. & $8.92_{8}$ & 402 & $168_{3}$ & 677 \\
\hline 5-1905 & C 37 & 400. & $8.89_{3}$ & 401 & 1689 & 677 \\
\hline $43-1905$ & $\mathbf{T}$ & 60.96 & $8.88_{3}$ & 393 & $172_{8}$ & 679 \\
\hline \multirow[t]{4}{*}{$98-1905$} & W & 0.379 & $8.85_{8}$ & 395 & $169_{2}$ & 668 \\
\hline & $W$ & 1.751 & $8.88_{1}$ & 402 & 1689 & 679 \\
\hline & $w$ & 3.703 & $8.92_{3}$ & 399 & $168_{i}$ & 673 \\
\hline & $w$ & 12.54 & $8.89_{4}$ & 400 & $168_{8}$ & 675 \\
\hline $143-1905$ & W & 1.534 & $8.82_{5}$ & 393 & 1747 & 687 \\
\hline $1-1906$ & C 19 & 95. & $8.91_{1}$ & 395 & $170_{2}$ & 672 \\
\hline $43-1906$ & C 19 & 50. & $8.82_{8}$ & 394 & $173_{9}$ & 685 \\
\hline \multirow[t]{2}{*}{$78-1906$} & $S$ & $15 . \times 4$ & $8.85_{4}$ & 134 & $522_{8}$ & 701 \\
\hline & $\mathbf{s}$ & $15 . \times 2$ & 8.860 & 135 & $519_{4}$ & 701 \\
\hline \multirow[t]{2}{*}{$137-1906$} & W & 0.8281 & $8.94_{4}$ & 293 & $228_{3}$ & 669 \\
\hline & W & 0.8295 & 8.943 & 291 & $229_{4}$ & 668 \\
\hline \multirow[t]{2}{*}{$138-1906$} & $w$ & 7.113 & 8.840 & 393 & 1739 & 683 \\
\hline & $w$ & 7.170 & $8.87_{5}$ & 404 & $168_{2}$ & 680 \\
\hline
\end{tabular}




\section{TABLE III-Continued}

Results obtained on the resistivity and temperature coefficient of copper at the Reichsanstalt

\begin{tabular}{|c|c|c|c|c|c|c|}
\hline $\begin{array}{l}\text { Resistance test } \\
\text { No. }\end{array}$ & $\begin{array}{c}\text { Form of } \\
\text { specimen } \\
\text { (W=wire) } \\
(\mathrm{W}=\text { sheet) } \\
(\mathrm{T}=\text { trolley) } \\
(\mathrm{C}=\text { cable) }\end{array}$ & $\begin{array}{l}\text { Cross section } \\
\text { in sq. } \mathrm{mm} \text {. }\end{array}$ & $\begin{array}{c}\text { Density, } \\
\text { d }\end{array}$ & $\begin{array}{c}\text { Temperature } \\
\text { coefficient at } \\
15^{\circ} \mathrm{C} \\
\alpha_{15}\end{array}$ & $\begin{array}{c}\text { Specific } \\
\text { resistance; } \\
\text { ohm, meter, } \\
\text { sq. mm. at } 15^{\circ} \mathrm{C} \\
\rho_{15}^{\prime}\end{array}$ & $\begin{array}{c}\text { Product } \\
\left(\alpha_{15}\right)\left(\rho_{15}^{\prime}\right)(10)^{7}\end{array}$ \\
\hline \multirow[t]{5}{*}{$200-1906$} & C 19 & 102.3 & $\left(8.88_{5}\right)$ & 0.00396 & 0.0171 & ... \\
\hline & w & 50.39 & $8.90_{4}$ & 399 & $169_{3}$ & 676 \\
\hline & w & 37.81 & $8.89_{3}$ & 398 & $171_{0}$ & 681 \\
\hline & $w$ & 28.29 & $8.88_{3}$ & 401 & $169_{5}$ & 680 \\
\hline & $w$ & 12.62 & $8.91_{6}$ & 370 & $182_{1}$ & 674 \\
\hline \multirow[t]{2}{*}{$36-1907$} & $w$ & 24.85 & $8.86_{3}$ & 397 & $171_{8}$ & 682 \\
\hline & $W$ & 24.85 & 8.869 & 395 & $171_{8}$ & 679 \\
\hline \multirow[t]{8}{*}{$36-1907$} & $w$ & 24.81 & $8.87_{8}$ & 395 & $171_{4}$ & 677 \\
\hline & $w$ & 24.86 & $8.86_{8}$ & 396 & $171_{\mathrm{s}}$ & 680 \\
\hline & $w$ & 24.87 & $8.85_{6}$ & 396 & $172_{4}$ & 682 \\
\hline & $w$ & 25.28 & $8.86_{6}$ & 389 & $172_{3}$ & 670 \\
\hline & w & 24.89 & $8.86_{6}$ & 392 & $171_{8}$ & 673 \\
\hline & w & 25.03 & $8.86 !$ & 397 & $172_{2}$ & 684 \\
\hline & $w$ & 25.34 & $8.86_{3}$ & 396 & $171_{9}$ & 681 \\
\hline & W & 25.21 & $8.86_{5}$ & 396 & $172_{4}$ & 683 \\
\hline $192-1907$ & W & 0.8043 & $8.88_{3}$ & 407 & $167_{9}$ & 683 \\
\hline 74-1908 & w & 25.34 & $8.86_{2}$ & 389 & $175_{1}$ & 681 \\
\hline $77-1908$ & W & 35.70 & $8.85_{7}$ & 401 & $170_{\overline{3}}$ & 684 \\
\hline \multirow[t]{8}{*}{$79-1908$} & W & 19.64 & 8.910 & 388 & $173_{7}$ & 674 \\
\hline & w & 17.40 & $8.91_{3}$ & 291 & $235_{4}$ & 685 \\
\hline & W & 19.53 & $8.91_{8}$ & 259 & $269_{3}$ & 697 \\
\hline & $\mathbf{w}$ & 20.56 & $8.89_{4}$ & 316 & $215_{4}$ & 681 \\
\hline & w & 3.264 & $8.92_{9}$ & 394 & $170_{5}$ & 672 \\
\hline & W & 7.332 & $8.93_{0}$ & 289 & $235 \tilde{5}$ & 681 \\
\hline & $w$ & 7.249 & $8.91_{9}$ & 281 & $241_{8}$ & 679 \\
\hline & w & 7.517 & $8.89_{5}$ & 282 & $241_{1}$ & 680 \\
\hline \multirow[t]{2}{*}{$2-1909$} & $w$ & 0.7836 & $8.93_{2}$ & 203 & $337_{8}$ & 686 \\
\hline & $w$ & 0.7821 & $8.92_{0}$ & 200 & $341_{4}$ & 683 \\
\hline 11-1909 & $s$ & $60 . \times 5$ & $\cdots$ & 149 & $475_{4}$ & 708 \\
\hline \multirow[t]{2}{*}{$12-1909$} & $w$ & 78.59 & $8.92_{t}$ & 396 & $169_{3}$ & 670 \\
\hline & $w$ & 78.57 & $8.92_{0}$ & 397 & $169_{2}$ & 672 \\
\hline 35-1909 & $w$ & 0.7667 & $8.92_{9}$ & 230 & $299_{T}$ & 689 \\
\hline
\end{tabular}


The mean value of $C$, Table IV, for the 48 samples is 0.00395 . For the 34 samples of conductivity above $94 \%$, the mean value of $C$ is $0.00393_{6}$. This agrees very well with the mean value $0.00393_{8}$ found in the present investigation, in which all of the samples were of conductivity above $94 \%$. For the 14 Reichsanstalt samples of low conductivity, varying from $32.8 \%$ to $92.5 \%$, $C$ varied irregularly between 0.00390 and 0.00406 . The maximum departure from the mean value, 0.00394 , is seen to be $3 \%$, a remarkably close agreement for such a wide range of conductivity. This is of particular interest to those who work with impure copper of low conductivity. For this result shows that the measurement of conductivity may be replaced by the measurement of temperature coefficient, with an accuracy sufficient for commercial purposes, even when the conductivity is as low as one-third that

\section{TABLE IV}

Reichanstalt results reduced to the form of expression used in Table I

\begin{tabular}{|c|c|c|c|}
\hline $\begin{array}{c}\text { Ohms per metergram } \\
\text { at } 20^{\circ} \mathrm{C} \text {, } \\
\delta_{20}\end{array}$ & $\begin{array}{l}\text { Percent conductivity, } \\
n_{\delta}\end{array}$ & $\begin{array}{c}\text { Temperature coefficient } \\
\text { at } 20^{\circ} \mathrm{C} \text {, } \\
\delta_{20}\end{array}$ & C \\
\hline .15313 & 99.93 & $0.00392_{2}$ & $0.00392_{5}$ \\
\hline .15325 & 99.85 & $394_{1}$ & 3947 \\
\hline 15319 & 99.89 & $393_{1}$ & 3935 \\
\hline .15649 & 97.78 & $385_{4}$ & $394_{1}$ \\
\hline .15287 & 100.10 & $387_{3}$ & 3869 \\
\hline 15299 & 100.02 & $394_{1}$ & 3940 \\
\hline .15352 & 99.68 & $391_{2}$ & $392_{5}$ \\
\hline .15312 & 99.94 & $392_{3}$ & $392_{4}$ \\
\hline .15716 & 97.37 & $385_{4}$ & $395_{8}$ \\
\hline .15466 & 98.94 & $387_{3}$ & $391_{4}$ \\
\hline .15651 & 97.77 & $386_{4}$ & $395_{2}$ \\
\hline .46588 & 32.85 & $133_{1}$ & $405_{2}$ \\
\hline .46318 & 33.04 & $134_{1}$ & 4059 \\
\hline .20718 & 73.86 & $288_{8}$ & 3910 \\
\hline .20814 & 73.52 & $286_{3}$ & $390_{1}$ \\
\hline .15672 & 97.64 & $385_{4}$ & $394 i$ \\
\hline .15227 & 100.49 & 3960 & $394_{1}$ \\
\hline .15492 & 98.77 & $388_{3}$ & 393 \\
\hline .15373 & 99.54 & $391_{2}$ & 3930 \\
\hline .15506 & 98.69 & $390_{3}$ & $395_{4}$ \\
\hline .15364 & 99.60 & $393_{1}$ & 3947 \\
\hline .15535 & 92.54 & $363_{3}$ & 3926 \\
\hline .15534 & 98.51 & $389_{3}$ & $395_{2}$ \\
\hline .15536 & 98.50 & $387_{3}$ & $393_{2}$ \\
\hline
\end{tabular}


TABLE IV

Reichanstalt results reduced to the form of expression used in Table I

\begin{tabular}{|c|c|c|c|}
\hline $\begin{array}{l}\text { Ohms per metergram } \\
\text { at } 20^{\circ} \mathbf{C} \text {, } \\
\delta_{20}\end{array}$ & $\begin{array}{l}\text { Percent conductivity, } \\
n_{\grave{\partial}}\end{array}$ & $\begin{array}{c}\text { Temperature coefficient } \\
\text { at } 20^{\circ} \mathrm{C} \text {, } \\
\alpha_{20}\end{array}$ & C \\
\hline .15516 & 98.62 & $0.00387_{3}$ & 0.003927 \\
\hline .15534 & 98.51 & $388_{3}$ & $394_{2}$ \\
\hline .15567 & 98.30 & $388_{3}$ & 3950 \\
\hline .15575 & 98.25 & $381_{6}$ & $388_{4}$ \\
\hline .15531 & 98.53 & 3845 & $390_{2}$ \\
\hline .15558 & 98.36 & $389_{3}$ & $395_{8}$ \\
\hline .15543 & 98.45 & $388_{3}$ & $394_{4}$ \\
\hline .15582 & 98.20 & $388_{3}$ & $395_{4}$ \\
\hline .15214 & 100.58 & 3989 & $396_{6}$ \\
\hline .15816 & 96.75 & $381_{6}$ & 3944 \\
\hline .15400 & 99.36 & $393_{1}$ & $395_{6}$ \\
\hline .15776 & 97.00 & $380_{6}$ & $392_{4}$ \\
\hline .21292 & 71.87 & $286_{B}$ & $399_{1}$ \\
\hline .24315 & 62.93 & $255_{7}$ & $406_{3}$ \\
\hline .19457 & 78.65 & $311_{1}$ & $395_{5}$ \\
\hline .15523 & 98.58 & $386_{4}$ & 3920 \\
\hline .21329 & 71.74 & 2849 & $397_{1}$ \\
\hline .21865 & 69.98 & $277_{1}$ & 396. \\
\hline .21745 & 70.37 & $278_{1}$ & $395_{2}$ \\
\hline .30471 & 50.22 & 2009 & 4000 \\
\hline .30752 & 49.76 & $198_{0}$ & 3979 \\
\hline .15407 & 99.32 & $388_{3}$ & 391 。 \\
\hline .15392 & 99.42 & $389_{3}$ & $391_{6}$ \\
\hline .27059 & 56.55 & $227_{4}$ & $402_{1}$ \\
\hline $\begin{array}{c}\delta_{20}= \\
\left(\rho^{\prime} 15\right)(d)+0.00299\end{array}$ & $\begin{array}{c}n_{\delta}= \\
\frac{0.153022}{\delta_{20}}\end{array}$ & $\begin{array}{l}\alpha_{20}= \\
\frac{a_{15}}{1+5 a_{15}}\end{array}$ & $\begin{array}{l}\mathrm{C}= \\
\frac{\alpha_{20}}{n_{\delta}}\end{array}$ \\
\hline
\end{tabular}

of pure copper. It might be mentioned that Lagarde, ${ }^{7}$ in 1888 , found that for samples composed of $98 \%$ copper and $2 \%$ tin, whose conductivity was one-third that of pure copper, the constant, $C$, was within $7 \%$ of $C$ for pure copper.

While all of the foregoing results for $C$, on samples of very low up to the highest conductivity, show a good agreement to commercial accuracy, the range of $94 \%$ to ror $\%$ conductivity is found at the Bureau of Standards to show a much closer agreement. For this range, which includes the good commercial copper 
furnished for use as electrical conductors, the average deviation of $C$ from the mean value $0.00393_{8}$ is only $0.00000_{8}$, or $0.2 \%$. Also, when the conductivity and temperature coeficient are altered by annealing or hard-drawing, $C$ has been found to remain constant within the experimental error.

Attention is called to the column of densities in the table of results obtained at the Reichsanstalt. The mean value is $8.89_{0}$. This is the same as the value in use in the Bureau of Standards and very widely elsewhere. It is hoped that this agreement in the results for temperature coefficient and density will assist in making possible an early international agreement on copper standards.

WASHINGTON, November 29, I9IO. 